\title{
GERMINATION FAILURES OF THE MAGNOLIA IN PUERTO RICO
}

\author{
By Melville T. CoOK
}

\begin{abstract}
During the summer of $1936 \mathrm{Mr}, \mathrm{L}$. R. Holdridge of the U. S. Forestry Service called my attention to germirtation failures of Magnolia portoricensis Bello. This and the very closely related species $M$. splendens Urban produce exceptionally fine woods but unfortunately both species are being exterminated very rapidly. Both species were very abundant at one time but at the present, it is practically impossible to find young trees in the forest. The Forestry Station has been trying to overcome his difficulty by sowing seeds in seed beds and growing seedlings for transplanting. $\mathrm{U}_{\mathrm{p}}$ to the present only one seedling of $M$. borinquensis has been produced although thousands of seeds have been sown.

When the first lot of material was brought to the writer it was found that the seeds in the pods were surrounded by masses of a white fungus mycelium and appeared to be packed in cotton. It was very naturally assumed that this fungus might be the important factor in the poor germination. The seeds from these pods were found to be dead but the fungus could not be detected on the inside.

However, it was noted that many seeds had never matured. Some of them were very small black scales, while others had attained a somewhat larger growth and then stopped before attaining full size. Therefore it was decided to make a study of the development of the embryo sac and embryo. A large number of seeds were sectioned in paraffin.

It was found that many of these ovules never developed an embryo sac. Others developed empty sacs. Whether they were really empty or appeared so as a result of faulty technique has not been determined. Most of the large seeds developed large sacs which were filled with an endosperm but the development has not been traced. Only three embryos have been found and in all cases the seeds were in an advanced stage of development and the two small embryos were in much larger seeds than the large embryo.
\end{abstract}

The pollen appeared to be normal. 
The $M$. splendens has not been studied by the writer but young trees are as rare for this species as for $M$. portoricensis.

This problem presents several questions. Why are such a small number of embryos produced? Undoubtedly the behavior of this species must have been quite different in the past otherwise it could not have been as abundant as it has been until very recently. It lost the power of producing viable seeds? If so, why?

Explanation for Figure on Page 53

1. Embryo sac about $1 / 2$ length of ovule.

2. Egg from same immersion.

3. Ant from same immersion.

4. Polars from same immersion.

5. Egg and one synergid.

6. Embryo in position.

7. Embryo in position.

8. Embryo in position.

9. Embryo in position.

10. Micropyle end of large seed almost mature. There is no embryo but the entire embryo sac was filled with a mass of endosperm. 

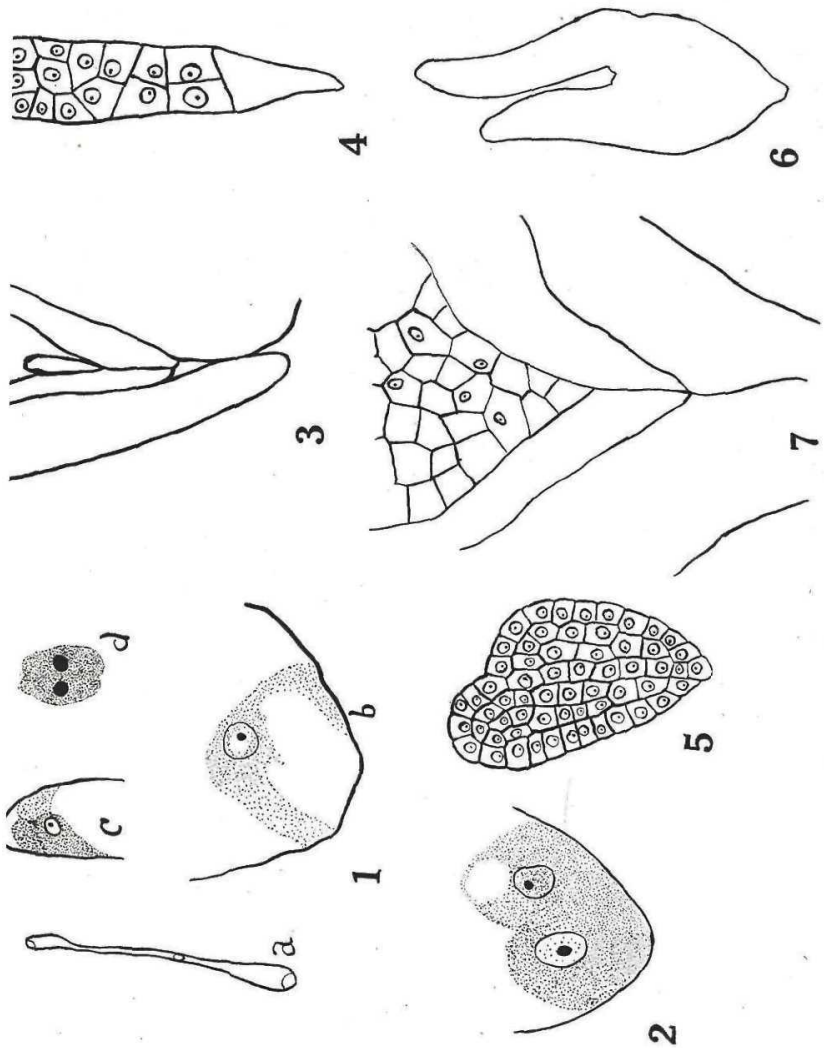